\section{Loyalitas Kreativitas \\ Aldi Masyarakat Kreatif}

P-ISSN 2722-2101, E-ISSN 2722-4201

Program StudiEkonomiManajemenUniversitasPamulang Jurnal LOKABMAS Kreatif Vol. 01, No. 02, Hal. 41-46

Email:jurnalkreatif.manajemen@gmail.com

\title{
PENDAMPINGAN PENYUSUNAN LAPORAN KEUANGAN BERBASIS EMKM MELALUI SI APIK
}

\author{
Lyandra Aisyah Margie, Afridayani, Yenni Cahyani, Khotimatus Sadiyah \\ Dosen Ekonomi Fakultas Ekonomi Universitas Pamulang \\ Email dosen02217@unpam.ac.id
}

\begin{abstract}
ABSTRAK
Pengabdian Kepada Masyarakat dapat diartikan sebagai respon akademik masyarakat kampus atas kebutuhan, tantangan atau persoalan yang dihadapi oleh masyarakat, baik secara langsung maupun tidak langsung. Tujuan umum dari mendampingi UMKM binaan Rumah Pemberdayaan Masyarakat adalah agar peserta dapat menganalisis dan memahami proses penyusunan laporan keuangan, menginput transaksi keuangan serta mengaplikasikan hasil pendampingan untuk menunjang penyusunan laporan keuangan melalui aplikasi Si Apik.

Adapun bentuk kegiatan dalam pelaksanaan pengabdian kepada masyarakat dengan tema penyusunan laporan keuangan. Dengan para pengajar dan narasumber yang dilibatkan adalah para Dosen Program Studi Akuntansi dari Universitas Pamulang. Hasil Pelaksanaan PKM yang dilakukan tanggal 24 sampai 28 februari 2020 adalah pemahaman UMKM yang didampingi mengenai pengetahuan dasar pembukuan keuangan dan kemampuan pengoperasian aplikasi Si Apik dalam rangka penyusunan laporan keuangan menjadi meningkat. UMKM yang didampingi pada kegiatan pengabdian kepada masyarakat kali ini sudah mampu melakukan proses instalasi dan mengoperasikan aplikasi untuk pencatatan keuangan usahanya sendiri. Hal ini dibuktikan juga dengan antusiasme peserta ketika mengikuti pendampingan sangatlah baik.

Laporan keuangan yang dihasilkan melalui aplikasi Si Apik pada dasarnya adalah laporan yang bukan bertujuan umum, namun sudah layak apabila digunakan oleh Lembaga Keuangan untuk penilaian kelayakan usaha dalam pemberian kredit sehingga laporan keuangan ini dapat digunakan untuk pengajuan pembiayaan pada Lembaga Keuangan.
\end{abstract}

\section{Kata Kunci: Penyusunan Laporan Keuangan, Si Apik}

\begin{abstract}
Community Service can be interpreted as an academic response from the campus community to the needs, challenges or problems faced by the community, both directly and indirectly. The general objective of assisting MSMEs fostered by Community Empowerment Houses is so that participants can analyze and understand the process of preparing financial reports, inputting financial transactions and applying the results of assistance to support the preparation of financial reports through the application of Apik Si.

The form of activities in the implementation of community service with the theme of the preparation of financial statements. The instructors and resource persons involved were Accounting Study Program Lecturers from Pamulang University. The results of the implementation of PKM conducted on 24 to 28 February 2020 is the understanding of MSMEs accompanied by basic knowledge of financial accounting and the ability to operate Si Apik applications in the framework of preparing financial statements to be increased. The MSME that was accompanied by community service activities this time was able to carry out the installation process and operate the application for the financial recording of
\end{abstract}




\section{Loyalitas Kreativitas \\ Aldi Masyarakat Kreatif}

P-ISSN 2722-2101, E-ISSN 2722-4201

Program StudiEkonomiManajemenUniversitasPamulang Jurnal LOKABMAS Kreatif Vol. 01, No. 02, Hal. 41-46

Email:jurnalkreatif.manajemen@gmail.com

its own business. This was also proven by the enthusiasm of the participants when attending the mentoring was very good.

The financial statements produced through the Si Apik application are basically reports that are not general purpose, but are feasible if used by Financial Institutions for evaluating business feasibility in granting credit so that these financial statements can be used for financing proposals at Financial Institutions.

\section{Keywords: Preparation of financial statements, Si Apik}

\section{PENDAHULUAN}

Perkembangan bisnis yang sangat cepat dan dinamis, menuntut para pelaku usaha khususnya pelaku Industri Mikro Kecil Menengah (IMKM) dan pelaku Usaha Mikro Kecil Menengah (UMKM) harus bergerak cepat mengikuti perkembangan zaman. Tujuannya agar dapat mempertahankan pasar dan konsumen serta memperluas jaringan bisnis. Tuntutan kemajuan teknologi pun dapat menjadi dua sisi mata uang berbeda yang dapat sangat membantu perkembangan usaha atau justru memperburuk keadaan usaha para pelaku UMKM / IMKM tersebut.

Pada dasarnya produk yang dihasilkan dan ditawarkan para pelaku UMKM tidak dapat dianggap remeh, memiliki ciri khas yang berbeda antar satu jenis produk yang sama pun sangat sering terjadi. Untuk itu kelihaian dalam memasarkan produk harus ditingkatkan, akibat tingginya persaingan. Tidak hanya soal pemasaran kesiapan pengelolaan 'rumah tangga' industri juga harus dipersiapkan sebaik mungkin, diantaranya kesiapan pengelolaan bisnis, pengelolaan keuangan usaha, pengelolaan stok barang sampai pada pengelolaan pelayanan konsumen. Untuk mempersiapkan 'rumah tangga' industri demi tetap bertahannya suatu usaha, para pelaku UKM perlu dibantu serta didampingi.

Di Kota Tangerang Selatan khususnya, para pelaku UKM banyak dibantu oleh Rumah Pemberdayaan Masyarakat (RPM). Rumah Pemberdayaan Masyarakat adalah sebuah lembaga nirlaba yang berfokus pada pelatihan dan pendampingan dalam berbagai programprogram pemberdayaannya. Selain itu, dalam setiap program Rumah Pemberdayaan Masyarakat menekankan kepada penguasaan bidang digital karena saat ini dunia menuju kehidupan yang serba otomatis, manusia mulai tergantikan oleh mesin, software dan peralatan lainnya yang dapat bekerja 24 jam tanpa istirahat sebagaimana manusia yang ada batasnya dalam bekerja. Dengan alasan itu maka penguasaan akan digital marketing sangat ditekankan untuk memenangi persaingan di dunia nyata baik tingkat lokal maupun internasional.

Salah satu penyebab UMKM sulit berkembang adalah sistem akuntansi yang buruk. Berbagai faktor menjadi penyebab. Termasuk masih banyak pelaku UMKM yang tidak mau memikirkan hal rumit seperti masalah akuntansi dan manajemen keuangan. Pengusaha UMKM terkadang tidak mengetahui secara riil jumlah uang yang dimiliki, berapa modal yang dikeluarkan, berapa hutang dan pihutang, serta apakah usaha mereka mendapatkan laba atau bahkan mengalami kerugian (Rinandiyana et, al., 2020).

Menurut Riyanto (2016 dalam Wiratama et, al., 2019), kelemahan lain yang dimiliki UMKM diantaranya adalah belum melakukan pembuatan laporan keuangan dan masalah perizinan yang sering diabaikan oleh pelaku UMKM. Kelemahan ini disebabkan beberapa faktor diantaranya anggapan bahwa melakukan pembukuan keuangan hanya membuang-buang waktu, masih gagap dengan perkembangan teknologi informasi akuntansi dan masih kurang pahamnya akan pentingnya informasi operasional usaha dalam bentuk pelaporan keuangan.

Padahal seperti yang kita tahu bahwa peran pelaporan keuangan usaha ini sangat penting untuk meningkatkan akses pembiayaan. Perlu adanya penyuluhan dan pendampingan mengenai standar keuangan yang berlaku bagi UMKM serta cara 


\section{Loyalitas Kreativitas \\ Aldi Masyarakat Kreatif}

P-ISSN 2722-2101, E-ISSN 2722-4201

Program StudiEkonomiManajemenUniversitasPamulang Jurnal LOKABMAS Kreatif Vol. 01, No. 02, Hal. 41-46

Email:jurnalkreatif.manajemen@gmail.com termudahnya dalam membantu pengelolaan keuangan baik secara manual maupun digital.

Salah satu upaya Bank Indonesia yang bekerjasama dengan Ikatan Akuntan Indonesia (IAI) adalah membuat Aplikasi Pencatatan Transaksi Keuangan (PTK) beserta panduan penggunaan aplikasi untuk mendorong peningkatan kapasitas usaha dan akses pembiayaan Usaha Mikro Kecil di seluruh Indonesia. Aplikasi PTK yang sekarang dikenal sebagai SI APIK (Sistem Informasi Aplikasi Pencatatan Informasi Keuangan) telah di luncurkan pada tahun 2015 sebagai sarana pencatatan transaksi keuangan yang terstandar dan sederhana. Selain itu pedoman aplikasi juga telah dikonfirmasikan dengan perbankan sehingga dapat memenuhi kaidah dan kriteria perbankan dalam melakukan penilaian kelayakan usaha (Wiratama et, al., 2019).

Berdasarkan uraian diatas, program pengabdian kepada masyarakat yang kami lakukan untuk UMKM yang berada di bawah naungan Rumah Pemberdayaan Masyarakat merupakan pendampingan penyusunan laporan keuangan melalui Si Apik yang merupakan aplikasi berbasis Android yang dikeluarkan oleh Bank Indonesia. Menurut Yuliani (2020), inovasi $\mathrm{Si}$ Apik sangat simple dan mudah digunakan sehingga UMK pada akhirnya memiliki laporan keuangan atas usaha yang dijalankan. Aplikasi inovasi Si Apik dapat digunakan untuk usaha perorangan dan berkelompok. Penggunaan $\mathrm{Si}$ Apik memberikan kemudahan dalam hal pengelolaan usaha sehingga jika usaha memerlukan pendanaan eksternal maka sangat mudah untuk melampirkan kondisi keuangan usaha.

\section{RUMUSAN MASALAH}

Berdasarkan analisis situasi permasalahan, dapat dirumuskan masalahnya sebagai berikut:

1. Apakah peserta dapat menganalisis dan memahami proses penyusunan laporan keuangan melalui aplikasi Si Apik?

2. Apakah peserta mampu menginput transaksi keuangan dengan menggunakan aplikasi Si Apik?

3. Apakah peserta dapat mengaplikasikan hasil pendampingan untuk menunjang penyusunan laporan keuangan melalui aplikasi Si Apik?

\section{TUJUAN PELAKSANAAN}

Tujuan yang ingin dicapai dalam kegiatan ini adalah sebagai berikut:

1. Agar peserta dapat menganalisis dan memahami proses penyusunan laporan keuangan melalui aplikasi Si Apik.

2. Agar peserta mampu menginput transaksi keuangan dengan menggunakan aplikasi Si Apik.

3. Agar peserta dapat mengaplikasikan hasil pendampingan untuk menunjang penyusunan laporan keuangan melalui aplikasi Si Apik.

\section{TINJAUAN PUSTAKA}

\section{Pengertian Usaha Menengah Kecil Mikro (UMKM)}

Sesuai dengan Undang-Undang Nomor 20 Tahun 2008 tentang Usaha Mikro, Kecil dan Menengah (UMKM) didefinisikan sebagai berikut:

1. Usaha Mikro adalah usaha produktif milik orang perorangan dan / atau badan usaha perorangan yang memenuhi kriteria usaha mikro menurut UU.

2. Usaha Kecil adalah usaha ekonomi produktif yang berdiri sendiri, yang dilakukan oleh orang perorangan atau badan usaha yang bukan merupakan anak perusahaan atau bukan cabang perusahaan yang dimiliki, dikuasai, atau menjadi bagian baik langsung maupun tidak langsung dari usaha menengah atau usaha besar yang memenuhi kriteria usaha kecil sebagaimana dimaksud dalam Undang-Undang ini.

3. Usaha Menengah adalah usaha ekonomi yang produktif yang berdiri sendiri, yang dilakukan oleh orang perorangan atau badan usaha yang bukan merupakan anak perusahaan atau bukan cabang perusahaan yang dimiliki, dikuasai atau menjadi bagian baik langsung maupun tidak langsung dari usaha kecil atau usaha besar yang memenuhi kriteria usaha kecil sebagaimana dimaksud dalam Undang-Undang ini. 


\section{Loyalitas Kreativitas \\ Aldi Masyarakat Kreatif}

P-ISSN 2722-2101, E-ISSN 2722-4201

Program StudiEkonomiManajemenUniversitasPamulang Jurnal LOKABMAS Kreatif Vol. 01, No. 02, Hal. 41-46

Email:jurnalkreatif.manajemen@gmail.com

\section{Penyusunan Laporan Keuangan Berbasis EMKM}

Tahapan penyusunan laporan keuangan dapat dibagi sebagai berikut (Bank Indonesia, 2015):

1. UMK berbentuk usaha perorangan dan badan usaha perorangan dapat menggunakan panduan akuntansi dalam Pedoman Teknis Pencatatan Transaksi Keuangan Usaha Mikro dan Kecil Perorangan sebagai dasar penyusunan laporan keuangannya. Tujuannya untuk mendorong UMK berbentuk usaha perorangan dan badan usaha perorangan dalam menyusun laporan keuangan.

2. UMK berbentuk badan usaha yang bukan badan hukum dapat menggunakan panduan akuntansi dalam Pedoman Teknis Pencatatan Transaksi Keuangan Usaha Kecil Badan Usaha Bukan Badan Hukum sebagai dasar penyusunan laporan keuangannya. Tujuannya untuk menyiapkan usaha kecil berbentuk badan usaha yang bukan badan hukum dalam menyusun laporan keuangan berdasarkan pada standar akuntansi keuangan, khususnya SAK ETAP.

3. Usaha berbentuk badan usaha berbadan hukum menggunakan ketentuan akuntansi dalam SAK ETAP sebagai dasar penyusunan laporan keuangannya. Tujuannya untuk menyiapkan badan usaha tersebut dalam menyusun laporan keuangan berdasarkan pada SAK.

4. Usaha berbentuk badan usaha berbadan hukum menggunakan ketentuan akuntansi dalam SAK sebagai dasar penyusunan laporan keuangannya.

Dalam tahap nomor 1 dan 2, laporan keuangan disusun berdasarkan pada pedoman akuntansi atau pedoman pencatatan transaksi keuangan, bukan berdasarkan pada standar akuntansi keuangan. Oleh karena itu, laporan keuangan yang dihasilkan bukan laporan keuangan untuk tujuan umum.

Dalam tahap 3 dan 4, laporan keuangan disusun berdasarkan pada standar akuntansi keuangan yang berlaku umum, sehingga laporan keuangan yang dihasilkan merupakan laporan keuangan untuk tujuan umum.

\section{Pengertian Aplikasi SI APIK}

Berdasarkan keterangan dari website-nya, aplikasi Akuntansi Pencatatan Informasi Keuangan (Si Apik) yang dikeluarkan oleh Bank Indonesia dan diluncurkan sejak pertengahan tahun 2016 ini ditujukan bagi usaha perorangan (mikro), usaha kecil maupun usaha menengah dalam memudahkan penyusunan laporan keuangan usahanya dengan melalui pencatatan transaksi sederhana. Untuk pencatatan usaha mikro hanya mencatat dan melaporkan sumber serta penggunaan dana, sementara usaha kecil menengah menyusun laporan yang lebih lengkap seperti laporan laba rugi, arus kas dan neraca sehingga lebih kompleks pencatatan dan laporan keuangannya. Si Apik bisa mencatat transaksi untuk berbagai jenis usaha, mulai dari manufaktur, perdagangan, jasa, pertanian, perikanan hingga peternakan. Si Apik bisa didownload melalui aplikasi playstore di android.

SI APIK memiliki standar pencatatan yang mengacu pada standar Ikatan Akuntansi Indonesia bersama dengan Bank Indonesia. Fitur aplikasi double entry (debet-kredit) dengan sistem input single entry (menurut jenis-jenis transaksinya). Pencatatan persediaan menggunakan metode FIFO (First In First Out) yang memudahkan pengguna (Wiratama et, al., 2019).

Tujuan dari Si Apik meliput tiga hal yaitu sebagai standar menyusun laporan keuangan untuk UMK, menjadi alat bantu dalam menyusun laporan keuangan serta membantu kreditur dalam menganalisis kemampuan UMK saat mengajukan kredit atau pembiayaan (Yuliani, 2020). Adapun fitur-fitur yang terdapat dalam aplikasi Si Apik adalah:

1. Pengisian periode awal transaksi

2. Penjualan hasil produksi tunai

3. Pembelian bahan material tunai

4. Biaya tenaga kerja

5. Laporan history transaksi

6. Laporan neraca

7. Laporan laba rugi dan saldo laba

8. Backup database

9. Restore database. 


\section{Loyalitas Kreativitas \\ Aldi Masyarakat Kreatif}

P-ISSN 2722-2101, E-ISSN 2722-4201

Program StudiEkonomiManajemenUniversitasPamulang Jurnal LOKABMAS Kreatif Vol. 01, No. 02, Hal. 41-46

Email:jurnalkreatif.manajemen@gmail.com

\section{METODE PELAKSANAAN}

Setelah dipahami, bahwa pencatatan akuntansi keuangan usaha para pelaku UMKM masih menjadi hal yang menyulitkan, maka pemecahan permasalahan ketidakdisiplinan pembukuan sederhana akibat kurangnya informasi mengenai standar akuntamsi keuangan yang berlaku bagi UMKM, dilakukan dengan beberapa pendekatan yang dilakukan secara bersama sama yaitu:

1. Berbasis kelompok Bapak/Ibu pelaku UMKM, seluruh kegiatan pengabdian masyarakat dilakukan kepada masyarakat dilakukan dengan menggunakan kelompok sebagai media belajar dan pendampingan, perencanaan dan memonitor dan evaluasi seluruh kegiatan pengabdian masyarakat.

2. Komprehensif, seluruh kegiatan pengabdian masyarakat dilakukan secara serentak terkait standar UMKM yang berlaku dan aplikasinya yang dilakukan melalui pelatihan dan pendampingan tenaga praktisi keuangan khusus UMKM.

3. Berbasis teknologi digital dengan pengembangan diri untuk beralih ke 'digital recording' sehingga mengefisiensikan waktu diantara aktivitas rantai produksi yang padat, serta menjadikan pencatatan lebih tepat dan akurat untuk pelaku UMKM naungan RPM Tangerang Selatan.

Selanjutnya ketiga metode di atas diimplementasikan dalam 4 (empat) tahapan yaitu (1) sosialisasi, (2) peningkatan kompetensi, (3) pendampingan (4) monitoring dan evaluasi. Diharapkan sosialisasi SAK EMKM dapat bekerja sama atau mendapat dukungan penuh dari pihak Bank Indonesia selaku creator dari SI APIK ini dan Ikatan Akuntan Indonesia (IAI) selaku sponsor dan pembuat Standar Akuntansi Keuangan Entitas Mikro Kecil Menengah.

\section{HASIL DAN PEMBAHASAN}

Pada awal pelaksanaan pengenalan diberi contoh cara instalasi aplikasi keuangan dan diberikan contoh cara penggunaan aplikasi dari pendataan asset usaha, kewajiban usaha, penjualan produk pelaku usaha, sampai dihasilkan laporan keuangan UMKM binaan. Kemudian mereka mempraktekkan sendiri, dan akhirnya dilepas namun tetap diberi pengawasan dan bimbingan.

Pendampingan kepada UMKM binaan juga dilakukan dengan metode diskusi, pendampingan ini berupa layanan konsultasi bila ditemui permasalahan tentang instalasi dan pengoperasian aplikasi keuangan tersebut. Pendampingan juga dilakukan melalui media teknologi komunikasi sekarang ini (telepon, sms, whatsapp dan social media) atau tatap muka secara langsung.

Evaluasi dilaksanakan pada masingmasing tahap kegiatan, baik dari kegiatan pengenalan, demonstrasi instalasi aplikasi, praktik langsung pengoperasian aplikasi, dan pendampingan. Evaluasi pada setiap tahapan untuk mengetahui tingkat keberhasilan setiap tahapan.

Setelah pemberian materi pengenalan Si Apik, beberapa pertanyaan muncul dari peserta pendampingan. Pertanyaan terkait akun yang dimiliki oleh UMKM binaan, terutama tidak adanya pemisahan antara beban operasional dengan beban rumah tangga dan tidak adanya depresiasi yang dibebankan. UMKM sendiri juga belum tertib administrasi keuangan pencatatan keuangan. Pengenalan Si Apik memberikan pengetahuan baru bagi UMKM tentang pencatatan keuangan berbasis aplikasi.

\section{KESIMPULAN DAN SARAN}

\section{Kesimpulan}

Dengan adanya kegiatan ini, pemahaman UMKM yang didampingi mengenai pengetahuan dasar pembukuan keuangan dan kemampuan pengoperasian aplikasi Si Apik dalam rangka penyusunan laporan keuangan menjadi meningkat. UMKM yang didampingi pada kegiatan pengabdian kepada masyarakat kali ini sudah mampu melakukan proses instalasi dan mengoperasikan aplikasi untuk pencatatan keuangan usahanya sendiri. Hal ini dibuktkan juga dengan antusiasme peserta khususnya Makhay_ResepPisan ketika mengikuti pendampingan sangatlah baik. 


\section{Loyalitas Kreativitas \\ Aldi Masyarakat Kreatif}

P-ISSN 2722-2101, E-ISSN 2722-4201

Program StudiEkonomiManajemenUniversitasPamulang Jurnal LOKABMAS Kreatif Vol. 01, No. 02, Hal. 41-46

Email:jurnalkreatif.manajemen@gmail.com

\section{Saran}

Berdasarkan kesimpulan diatas, maka saran yang dapat disampaikan adalah:

1. Bagi pemiliki usaha, diharapkan pelatihan yang sudah diberikan baiknya diterapkan dan diaplikasikan secara terus menerus dan bertahap, sehingga program pendampingan penyusunan laporan keuangan ini dapat memberikan manfaat bagi kemajuan usaha UMKM yang didampingi.

2. Sebaiknya program kegiatan pengabdian kepada masyarakat (PKM) ini dapat dilakukan secara berkelanjutan agar ada kesinambungan antara program yang satu dengan yang lainnya. Dengan adanya kesinambungan program ini diharapkan dapat memberi manfaat yang oprimal bagi seluruh masyarakat terkhusus subjek PKM yang dilakukan.

\section{DAFTAR PUSTAKA}

Bank Indonesia. (2015). “ Pedoman Teknis Pencatatan Transaksi Keuangan Usaha Kecil Badan Usaha Bukan Badan Hukum Sektor Manufaktur". Di unduh dari https://www.bi.go.id/id/umkm/penelitian/ nasional/kajian/Pages/PedomanUmumPedoman-Teknis-dan-Modul-PTKuntuk-UMK.aspx pada tanggal 20 Juni 2020

Pasaribu, V. L. D., Agrasadya, A., Shabrina, N., \& Krisnaldy, K. (2020). MENJADI ENTERPRENEUR MUDA YANG MEMILIKI JIWA LEADERSHIP UNTUK MENGHADAPI MASA DEPAN. $A b d i$ Laksana, 1(1)

Pasaribu, V. L. D., Elburdah, R. P., Sudarso, E., \& Fauziah, G. (2020). PENGGUNAAN MANAJEMEN WAKTU TERHADAP PENINGKATAN PRESTASI BELAJAR DI SMP ARAISIYAH. Jurnal ABDIMAS, 1(1)

Pasaribu, V. L. D., Susanti, F., \& Hartuti, E. T. K. (2019). MEMOTIVASI SISWA DAN SISWI SMK LETRIS INDONESIA DI
DALAM MENENTUKAN PILIHAN UNTUK MELANJUTKAN PENDIDIKAN ATAU BEKERJA SETELAH LULUS SEKOLAH. Jurnal Pengabdian Dharma Laksana, 1(2), 161-172.

Pasaribu, V. L. D., Oktrima, B., Prabowo, B., Arianto, N., \& Haryoko, U. B. (2020). PROGAM PENDAMPINGAN DAN

PENYELENGGARAAN PENDIDIKAN ANAK PADA USIA DINI TERHADAP PRESTASI BELAJAR DILINGKUNGAN RT 020 RW 009. KEL GIRI PENI. KEC WATES. YOGYAKARTA. JURNAL LOKABMAS KREATIF, 1(1), 71-75.

Pasaribu, V. L. D., Sulaiman, S., Sutiman, S., Thaharudin, T., \& Purnomo, B. Y. (2020). PENGENALAN LETAK POSYANDU TERDEKAT DIKELURAHAN PISANGAN DENGAN MANAJEMEN PEMASARAN REVOLUSI 4.0 UNTUK MENINGKATKAN PENGETAHUAN MASYARAKAT LETAK DAN FUNGSI POSYANDU TERDEKAT PADA KELURAHAN PISANGAN. DEDIKASI PKM, l(1), 105-110.

Pasaribu, V. L. D., \& Krisnaldy, K. (2019). Manajemen Risiko dan Asuransi.

Rinandiyana, L, R., Kusnandar, D, L., \& Rosyadi, A. (2020). Pemanfaatan Aplikasi Akuntansi Berbasis Android (SiApik) Untuk Meningkatkan Administrasi Keuangan UMKM. Jurnal Qardhul Hasan: Media Pengabdian kepada Masyarakat, 6(1), 73-78. p-ISSN 2442-3726 e-ISSN 2550-1143

Rumah Pemberdayaan Masyarakat pada laman https://rumahpemberdayaan.com/

Undang-Undang Nomor 20 Tahun 2008 tentang Usaha Mikro Kecil dan Menengah

Wiratama, Bayu., Kriswanto, Rahayu, Sri., Nugraha, Amhar Rias., \& Satriawan, Yudha. (2019). Penerapan Aplikasi Keuangan Berbasis Android "Si Apik" pada Penyusunan Laporan Keuangan UMKM Biofarmakaka Desa Limbangan Kendal. Rekayasa 17 (1) (2019): 16-24 


\section{Loyalitas Kreativitas \\ Aldi Masyarakat Kreatif}

P-ISSN 2722-2101, E-ISSN 2722-4201

Program StudiEkonomiManajemenUniversitasPamulang Jurnal LOKABMAS Kreatif Vol. 01, No. 02, Hal. 41-46 Email:jurnalkreatif.manajemen@gmail.com

Yuliani, Rasyid Hs Umrie \& Bakar, Samadi W. (2020). Peningkatan Literasi Keuangan Melalui Inovasi Si Apik Bagi UMK Desa Tanjung Raya Kabupaten Lahat. JAbdipamas Vol. 4 No. 1 April 2020. ISSN : 2581-1320 (Print) ISSN : 2581-2572 (Online)

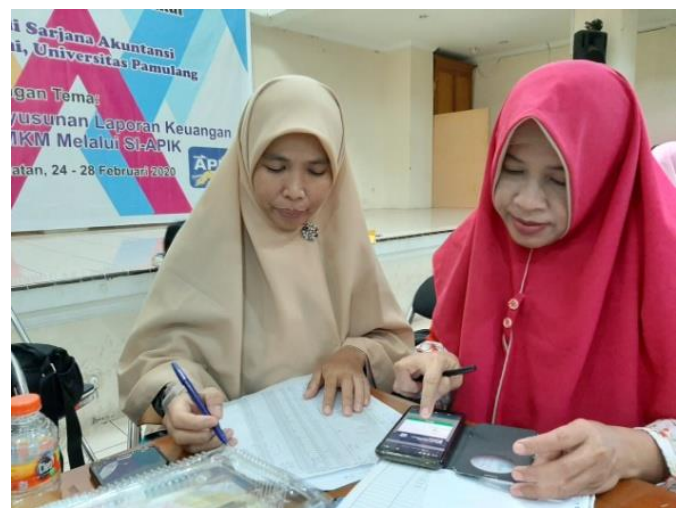

\section{DOKUMENTASI FOTO KEGIATAN}
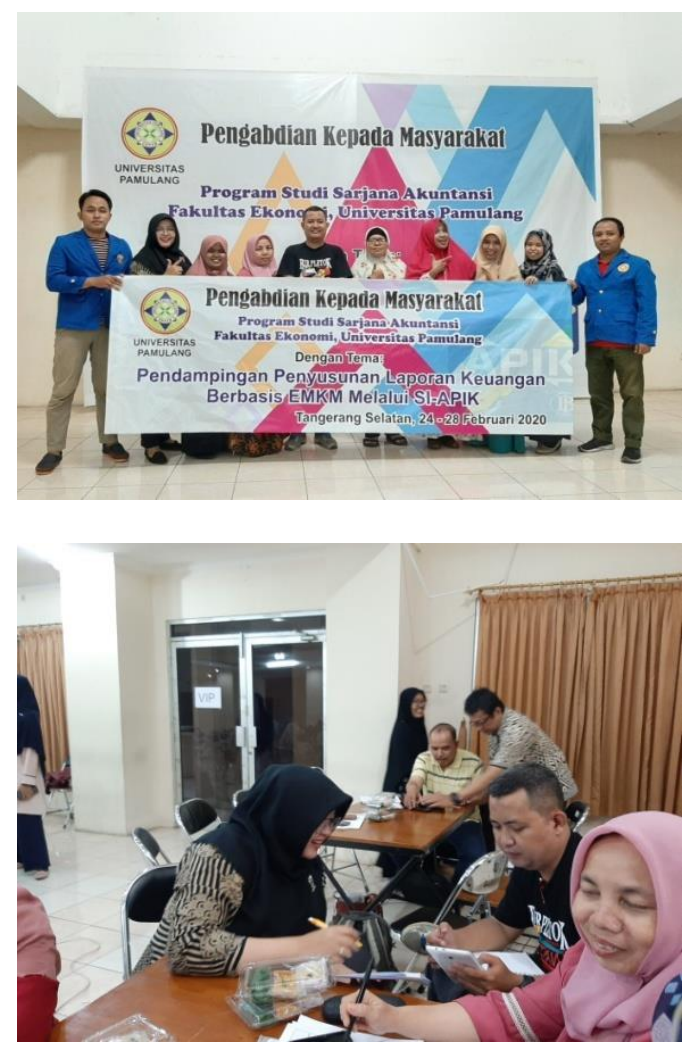